\title{
Testing hypotheses about temporary and persistent effects of otter trawling on infauna: changes in diversity rather than abundance
}

\author{
Stefán Áki Ragnarsson ${ }^{1, *}$, Mats Lindegarth ${ }^{2}$ \\ ${ }^{1}$ Marine Research Institute, Skúlagata 4, PO Box 1390, 121 Reykjavík, Iceland \\ ${ }^{2}$ Department of Marine Ecology - Tjärnö, University of Gothenburg, Tjärnö, 45296 Strömstad, Sweden
}

\begin{abstract}
A field experiment was conducted to examine the short- and long-term effects of otter trawling on a macrobenthic infaunal community in shallow subtidal waters of Faxaflói Bay (SW Iceland) that had never been trawled before. The experimental design consisted of 4 sites trawled 10 times and 4 areas left undisturbed (controls). Sampling of fauna and sediments was carried out in June 1997, immediately after trawling, and subsequently 2 and 7 mo later, in order to investigate longer term impacts of trawling. No significant treatment effects could be detected on total abundance or on multivariate structure, and tests for individual species revealed only a single short-term effect (for the bivalve Thyasira flexuosa). However, trawling affected several aspects of diversity with significant short-term reduction in species richness and persistent effects on the Shannon-Wiener index. Power analysis revealed that larger changes were needed to detect changes in abundance compared to measures of diversity. Analyses of qualitative changes revealed a decreasing trend in abundance of the majority of taxa (especially the rarer ones) immediately after trawling. This was the most likely cause for the reduced diversity and the augmented small-scale variability in species richness. The size of initial impacts and the persistence of effects were largely consistent with those of previous studies in similar environments. Similar to other types of environmental impacts in aquatic environments, our analyses reveal that impacts of trawling on measures of diversity can be detected at a high statistical power and that larger effects are necessary to detect impacts on abundances.
\end{abstract}

KEY WORDS: Otter trawl · Experimental fishing · Infauna - Variability · Analysis of variance · Iceland $\cdot$ Diversity $\cdot$ Power analysis

Resale or republication not permitted without written consent of the publisher

\section{INTRODUCTION}

Fishing with towed bottom gear is a regional and global threat to the diversity and functioning of marine benthic habitats (e.g. Collie et al. 1997, Kaiser et al. 2002, 2006, Gray et al. 2006). The effects of trawling and dredging range from very drastic impacts, such as destruction of vulnerable habitats like cold-water corals (e.g. Fosså et al. 2002, Costello et al. 2005, Wheeler et al. 2005) and sponges (e.g. Wassenberg et al. 2002), to more subtle effects like alterations in benthic production processes (Jennings et al. 2001). The magnitude and persistence of fishing disturbance depends on a large number of factors, such as the type of fishery and the level of natural disturbance (e.g. Kaiser et al. 2006). Therefore, in order to provide guidance on levels of fishing that are sustainable in terms of impact to the environment, research is needed to unravel the magnitude, persistence and resilience of trawl effects under different environmental conditions and regimes (e.g. Gray et al. 2007, Løkkeborg 2007).

The most commonly used type of towed bottom fishing gear in the North Atlantic is the otter trawl (Ragnarsson \& Steingrímsson 2003), of which the 2 components - otter-boards and the ground-rope-are primarily responsible for the sediment disturbance. The otter-boards scour the seabed, generally resulting in formation of tracks of variable depth (e.g. Gilkinson et 
al. 1998). The area of seabed disturbed by the otterboards is, however, very small relative to the area swept by the ground-rope (e.g. Krost et al. 1990). The ground-rope, which is generally fitted with 'rock hoppers', scours the upper sediment layers, thus changing the sediment structure and reducing both the nutritional sediment quality and the amount of flocculated matter (Schwinghamer et al. 1998, Watling et al. 2001).

The majority of experimental studies on the effects of otter-trawling in soft sediments have reported relatively minor effects in comparison to other types of gear, such as beam-trawls (Kaiser et al. 2006). Conclusions about effects of trawling on assemblages in soft sediments differ among studies in magnitude, persistence and in terms of the proportion of variables affected. This variability in response is partly driven by differences in the physical environment (e.g. hydrodynamic regime, depth, sediment characteristics and habitat type) and in the species' properties (e.g. lifehistory traits, lifestyle and feeding guild; Kaiser et al. 2006). In sandy habitats, the observed impacts have generally been small and few. In muddy habitats, however, otter-trawls appear to cause more complex impacts, with a short-term decrease in abundances of individual taxa $(<1 \mathrm{wk})$, followed by increased abundances over longer periods of time, ranging from weeks to months (Kaiser et al. 2006). Another type of impact that has been attributed to otter-trawling is an increase in small-scale spatial and temporal variability of faunal assemblages (Lindegarth et al. 2000a). Thus, it appears that otter-trawling might affect benthic assemblages selectively and in a number of ways.

Evidence of impacts of trawling comes from both observational and manipulative studies. Manipulative experiments offer unique opportunities to test hypotheses about causal relationships and to estimate the magnitude and nature of effects (e.g. Underwood 1997). Properly planned, conducted and interpreted, such experiments allow researchers to separate effects of experimental treatments without being confounded by variability caused by other factors that are not controlled by the experimenter. While such experiments are ideally conducted at large spatial and temporal scales, in order to optimise relevance and realism (Thrush et al. 1998), practical constraints and costs often limit their reliability (e.g. Lindegarth et al. 2000b). In particular, the prevalence of spatial and temporal variability in these systems (e.g. Currie \& Parry 1996, Kaiser \& Spencer 1996, Lindegarth et al. $2000 a, b)$ combined with a small number of independent replicate units may lead to insufficient statistical power (i.e. increased risk of Type 2 errors; e.g. Mapstone 1995) or confounding if experimental treatments are not replicated (i.e. Type 1 errors; e.g. Hurlbert 1984, Underwood 1994, Lindegarth et al. 2000b).
In the present study we tested hypotheses about effects of otter trawling on abundance and diversity of infaunal communities in an area that had never been trawled before. Using a multifactorial experimental design, we simultaneously quantified and tested for the existence of any temporary and persistent effects on means and on small-scale spatial variability of benthic assemblages in muddy areas off the coast of Iceland following experimental trawling. In order to allow independent estimates of the effects of trawling and of spatial and temporal variability associated with factors other than trawling, the experimental design involved 4 areas that were experimentally trawled and 4 areas that remained undisturbed. Furthermore, the results of the experiment were evaluated by assessing the minimum size of impacts that were necessary to be detected with an acceptable statistical power.

\section{MATERIALS AND METHODS}

Study site and experimental design. The study site $(1 \times 3.7$ km; Fig. 1) is located north of the Reykjanes peninsula in Stakks Fjord (Faxaflói Bay), centred at $63^{\circ} 59^{\prime} \mathrm{N}, 22^{\circ} 28^{\prime} \mathrm{W}$. The whole of Faxaflói Bay (Fig. 1) has been closed to trawl fisheries since 1958 (Directorate of Fisheries, unpubl. data). Since 1991, Icelandic skippers are obliged to keep logbook records on the locations of all hauls down to a spatial resolution of 1' latitude and 1' longitude. The analysis of logbook data (Marine Research Institute and the Directorate of Fisheries database) showed that no trawling activity took place within Faxaflói Bay between 1991 and 2003. Furthermore, there is no evidence of demersal fishing prior to 1991 within Faxaflói Bay. The only towed mobile bottom gear allowed in Faxaflói Bay is the Danish

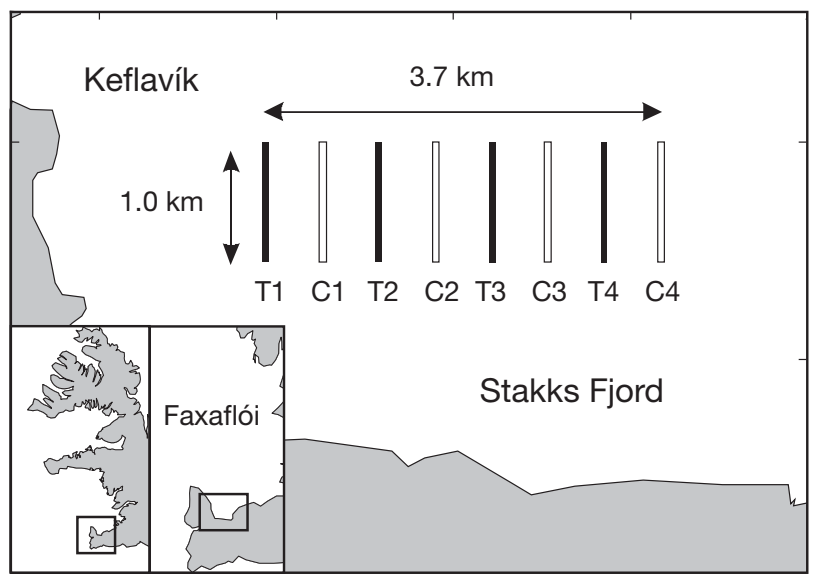

Fig. 1. Map of the study area in Stakks Fjord (location within Iceland shown in inserted maps) and the locations of the 4 trawled ( $\mathrm{T} 1$ to $\mathrm{T} 4$ ) and the 4 untrawled control ( $\mathrm{C} 1$ to $\mathrm{C} 4)$ plots 
seine, and analysis of logbook data shows that fishing with this gear has not taken place within the study area.

The depth within the study site ranged from 32 to $35 \mathrm{~m}$. The sediment can be categorised as mud or muddy sand with the amount of silt varying from 46 to $54 \%$ by weight (Bale \& Kenny 2005). Storms are frequent and due to shallow depth at the study site, storm-induced suspension of sediments is likely to be considerable.

In June 1997, an experiment on the effects of otter trawling on infauna was initiated. Eight plots, separated by about $400 \mathrm{~m}$, were located within the study site (Fig. 1). Four of these were trawled 10 times, whereas the remaining 4 were left undisturbed as control plots. This intensity of trawling represents the upper limits of yearly trawling in Icelandic waters (Ragnarsson \& Steingrímsson 2003). Sampling of fauna and sediments was carried out immediately after trawling (June 1997) and subsequently 2 and 7 mo after trawling (August 1997 and January 1998). Locations for grab samples were assigned a priori at random along the midline of each plot. During sampling within the trawled plots, care was taken that samples were collected more or less along the midline of the trawl swath. Within each plot, samples were collected from 8 stations in August and January, but from 6 stations in June. From each station, 2 replicate samples were collected with a Shipek grab $\left(0.041 \mathrm{~m}^{2}\right)$. Thus, a total of 352 samples were planned for the study, but unfortunately 7 and 5 samples from trawled and untrawled plots, respectively (3.5\% of the samples), were lost during handling at sea and in the laboratory.

The trawling was carried out with an otter trawl fitted with $1100 \mathrm{~kg}$ polyvalent otter-boards. The lengths of head-rope and bridles were 25 and $46 \mathrm{~m}$, respectively, and the net was rigged with rockhoppers measuring $45 \mathrm{~cm}$ in diameter. The distances between the wing ends and the otter-boards during towing (measured at a speed of 3.5 knots with SCANMAR acoustic instrumentation attached to the headline) were 13.3 and $39.6 \mathrm{~m}$, respectively. During towing, the vessel followed, as closely as possible, the midline of the first trawl path. The position of the vessel during towing was recorded to an accuracy of $\pm 10 \mathrm{~m}$ using dGPS (differential global positional system), relayed through the navigational program package MaxSea (Radiomidun). In the MaxSea program, the distance between trawl tracks could be measured with high accuracy. Based on this information, the width of the swath within each of the 4 trawled areas was estimated to range from 80 to $120 \mathrm{~m}$. Due to the shallow depth at the site, the offset of the trawl relative to the vessel during towing was considered to be minor.

Sample processing. Samples for faunal analysis were sieved on board through a $0.5 \mathrm{~mm}$ mesh and fixed in buffered $4 \%$ formaldehyde with seawater. In the laboratory, all animals were sorted, identified to the lowest taxonomic level possible (usually species or genus), counted and preserved in $70 \%$ alcohol. The most abundant species in the samples was Myriochele oculata, but this polychaete becomes easily fragmented during sample processing. To obtain reliable abundance estimates of $M$. oculata, all tubes from a single sample were dissected, revealing that $57 \%$ of all fragments of this polychaete contained heads. In subsequent data analysis, all M. oculata fragments were counted and multiplied with 0.57 to obtain corrected abundance estimates. Although this estimate was based on a single sample, dissecting more tubes to obtain more robust estimates would have been extremely time consuming since the average number $( \pm S D)$ of tube fragments per sample was $237( \pm 141.4)$.

Statistical analyses and hypotheses about impacts of trawling. The linear model used for uni- and multivariate hypothesis testing contained 4 factors: 'treatment' ( $\mathrm{Tr}_{\text {; }}$ trawled versus control plots; number of levels, $a=2$ ) and 'time' ( $\mathrm{Ti}_{;}$0, 2 and 7 mo after trawling; number of levels, $b=3$ ) were fixed factors, while 'plots' $\mathrm{Pl}(\mathrm{Tr})$ and 'station' $(\mathrm{St}[\mathrm{Tr}, \mathrm{Ti}, \mathrm{Pl}] ; 6$ or 8 per plot and time; number of levels, $c=6$ or 8 , each consisting of 2 samples) were random, nested factors. The $\mathrm{Pl}(\mathrm{Tr})$ and $\mathrm{St}(\mathrm{Tr}, \mathrm{Ti}, \mathrm{Pl})$ factors tested for significant differences among plots between treatments and for differences among stations within plots, respectively. Despite the apparent analytical complexity, relevant tests for ephemeral and persistent effects of trawling are identified a priori for both multi- and univariate analyses. A persistent effect, i.e. difference between trawled and control plots, which appears immediately after trawling and does not change throughout the experiment, can be identified as a significant effect of Tr. A temporary effect where the difference between trawled and control plots differ among times is, however, detected as a significant interaction between the experimental treatment and time, $\operatorname{Tr} \times \mathrm{Ti}$.

Hypotheses about multivariate effects on abundance and composition of whole assemblages were tested using permutational multivariate ANOVA (PERMANOVA; Anderson 2001, McArdle \& Anderson 2001). Due to limitations with unbalanced data, samples were randomly excluded to achieve equal sample sizes in all combinations of plots and times $(n=6)$ and consequently the factor $\mathrm{St}(\mathrm{Tr}, \mathrm{Ti}, \mathrm{Pl})$ was removed from the model. These modifications may have some effects on the precision of multivariate means within plots at individual times, but, because they do not affect the degrees of freedom for the important error terms, the power and reliability of the test for effects of trawling ( $\mathrm{Tr}$ and $\mathrm{Tr} \times \mathrm{Ti}$ ) will not be severely affected. Furthermore, the differences in the structure 
of assemblages in trawled and untrawled plots were visualised using non-metric multidimensional scaling (nMDS; Plymouth Routines in Multivariate Ecological Research; Clarke \& Warwick 1994). Ordinations of samples were done at individual times, and, to visualise changes among times, we plotted ordinations using centroids for individual plots at all times. PERMANOVA and nMDS ordinations were based on the Bray-Curtis measure of similarity on square-roottransformed data.

Univariate analysis of variance (ANOVA) was used to test hypotheses about persistent $(\mathrm{Tr})$ and temporary effects $(\mathrm{Tr} \times \mathrm{Ti})$ of trawling on averages of total number of individuals and taxa, the 2 measures of species diversity (Shannon-Wiener's and Simpson's indices) and on abundances of individual taxa. To achieve a complete interpretation of temporary effects, the interaction was complemented with a posteriori tests. We used Student-Newman-Keuls (SNK) procedures to evaluate at which sampling occasion there was a difference between trawled and untrawled areas. To maximise the statistical power of all univariate tests, post hoc pooling was applied to insignificant terms ( $\mathrm{p}>0.25)$, mainly $\mathrm{Pl}(\mathrm{Tr}), \mathrm{Ti} \times \mathrm{Pl}(\mathrm{Tr})$ and $\mathrm{St}(\mathrm{Tr}, \mathrm{Ti}, \mathrm{Pl})$ (Winer et al. 1991, Underwood 1997). Due to the slightly unbalanced design (more samples collected in August and January compared to June), the Type III sums of squares were used (Henderson 1953). Prior to analyses, data were $\log _{10}(\mathrm{x}+1)$ transformed to normality.

For univariate analyses, possible persistent effects of trawling on small-scale variability (variability among samples) were examined using 2-tailed $F$-tests at $\alpha=$ 0.025 (Underwood 1994). This was done by partitioning the residual variability into that estimated for trawled and control plots, respectively.

Power analyses. In order to evaluate the capacity of the experiment to detect any persistent or temporary effects of a given magnitude, we calculated the statistical power of a range of effect sizes. By defining a desired statistical power of $80 \%$ (which corresponds to a Type 2 error of 0.2 ), we estimated a minimum detectable effect size (MDES; Quinn \& Keough 2002) for the total number of individuals, 3 measures of diversity and for the abundance of the 3 most common and the 3 least common taxa. Calculation of power requires that alternatives $\left(H_{\mathrm{A}}\right)$ to the null hypothesis $\left(H_{0}\right)$ are defined. First, analyses of the power to detect persistent effects, i.e. the factor $T r$, were modelled by assuming a proportional decrease $(D=0.02$ to 0.5$)$ in the trawled locations compared to the controls such that:

$$
H_{\mathrm{A}, \mathrm{Tr}}: \bar{X}_{\text {Trawl }} \times D<\bar{X}_{\text {Control }}
$$

For each level of $D$, power was estimated by calculating the non-centrality parameter $\lambda$ from:

$$
\lambda=\frac{b c n \sum_{i=1}^{a}\left(\bar{x}_{i}-\overline{\bar{X}}\right)^{2}}{\text { MSerror }}
$$

where MSerror is the appropriate error term of the $F$-test, $\bar{x}_{i}$ is the mean for the $i$ th treatment and $x$ is the overall mean. Finally, the probability of detecting a certain effect was obtained from the non-central F-distribution using the actual degrees of freedom used in the test (i.e. when possible, df for the pooled mean square were used).

Second, analyses of the power to detect temporary effects, i.e. the interaction $\operatorname{Tr} \times \mathrm{Ti}$, were modelled by assuming that a proportional decrease in the trawled locations would only occur at the first time of sampling, while at the other times there would be no differences between trawled and control plots. Therefore, the alternative hypothesis of interest was:

$H_{\mathrm{A}, \operatorname{Tr} \times \mathrm{Ti}}$ : time $1, \overline{\mathbf{x}}_{\text {Trawl }} \times D<\overline{\mathbf{x}}_{\text {Controli }}$ time $2, \overline{\mathbf{x}}_{\text {Trawl }} \times D$ $=\bar{x}_{\text {Control }}$ and time $3, \bar{x}_{\text {Trawl }} \times D=\bar{x}_{\text {Control }}$ and $\lambda$ was calculated as:

$$
\lambda=\frac{\operatorname{cn} \sum_{i=1}^{a} \sum_{j=1}^{b}\left(\bar{x}_{i j}-\overline{\mathbf{x}}_{i}-\overline{\mathbf{x}}_{j}+\overline{\bar{x}}\right)^{2}}{\mathrm{MS}_{\mathrm{error}}}
$$

where $\bar{X}_{i j}$ is the mean of the $i$ th treatment at the $j$ th time of sampling, $\bar{x}_{i}$ is the mean of the $i$ th treatment, $\bar{x}_{j}$ is the mean of the $j$ th time and $\bar{x}$ is the overall mean.

\section{RESULTS}

\section{General observations}

A total of 160 taxa representing 138577 ind. were recorded during the course of the present study. Two taxa dominated in abundance, the tube-building polychaete Myriochele oculata and bivalves belonging to the genus Abra, accounting for 38 and $27 \%$ of the total abundance, respectively. The polychaetes Paraonis sp., Cossura longocirrata, Scoloplos armiger, Pholoe minuta, Sternaspis scutata and Eteone longa contributed $25 \%$ to the total abundance. Polychaetes, bivalves, crustaceans and other groups comprised 69.6, 29.3, 0.7 and $0.3 \%$ of the total abundance, respectively.

\section{Effects on multivariate structure}

Multivariate tests of hypotheses about effects of trawling on the whole benthic community found no significant persistent or temporary effects (Table 1). This suggests that there was no consistent difference between treatments at all times combined, nor were there any consistent differences in the way the 2 treatments changed over time. Consistent with this result, was the lack of 
Table 1. Tests of fishing on the overall assemblage structure using permutational multivariate analysis of variance (PERMANOVA) on Bray-Curtis dissimilarities on square-root-transformed non-standardised data. Probabilities were determined by unrestricted permutation of raw data using correct permutable units. Unique values: no. of unique values in permuted distribution

\begin{tabular}{|c|c|c|c|c|c|c|c|}
\hline Source & df & SS & MS & $F$ & $\mathrm{p}$ & $\begin{array}{c}\text { Permutable } \\
\text { units (n) }\end{array}$ & $\begin{array}{c}\text { Unique } \\
\text { values (n) }\end{array}$ \\
\hline Treatment $=\mathrm{Tr}$ & 1 & 679 & 679 & 0.342 & 1 & 8 & 915 \\
\hline Time $=\mathrm{Ti}$ & 2 & 10966 & 5483 & 8.356 & 0.001 & 24 & 868 \\
\hline Plot $(\mathrm{Tr})=\mathrm{Pl}(\mathrm{Tr})$ & 6 & 11930 & 1988 & 3.99 & 0.001 & 192 & 997 \\
\hline $\mathrm{Tr} \times \mathrm{Ti}^{\prime}$ & 2 & 1358 & 679 & 1.03 & 0.423 & 24 & 910 \\
\hline $\mathrm{Ti} \times \mathrm{Pl}(\mathrm{Tr})$ & 12 & 7874 & 656 & 1.32 & 0.004 & 192 & 1000 \\
\hline Residual & 168 & 83655 & 497 & & & & \\
\hline Total & 191 & 116464 & & & & & \\
\hline
\end{tabular}

clear separation among samples from trawled and untrawled plots in nMDS ordinations based on data from the whole experiment or at individual times (Fig. 2). Nevertheless, there was a highly significant change in community structure over time (Table 1, Fig. 2). Furthermore, community structure differed significantly among plots, and the significant $\mathrm{Ti} \times \mathrm{Pl}(\mathrm{Tr})$ interaction showed that trends in community structure over time were not consistent among plots. These findings were supported by the nMDS ordination, which revealed that the spatial and temporal variation among plots located in the eastern half (T3 to C4) was much greater compared to that in the western half ( $\mathrm{T} 1$ to $\mathrm{C} 2$ ) of the study area (Fig. 2).

\section{Effects on total abundance and diversity}

The overall qualitative pattern of total abundance and diversity is that all variables increased during the experiment (Fig. 3). Furthermore, the mean values for all variables were smaller in the trawled area compared with the controls immediately after fishing, but, on subsequent sampling occasions, the rate of increase tended to be larger in trawled areas. In consistency with these observations, tests using ANOVA showed a range of different immediate (days) and long-term (months) effects on measures of diversity
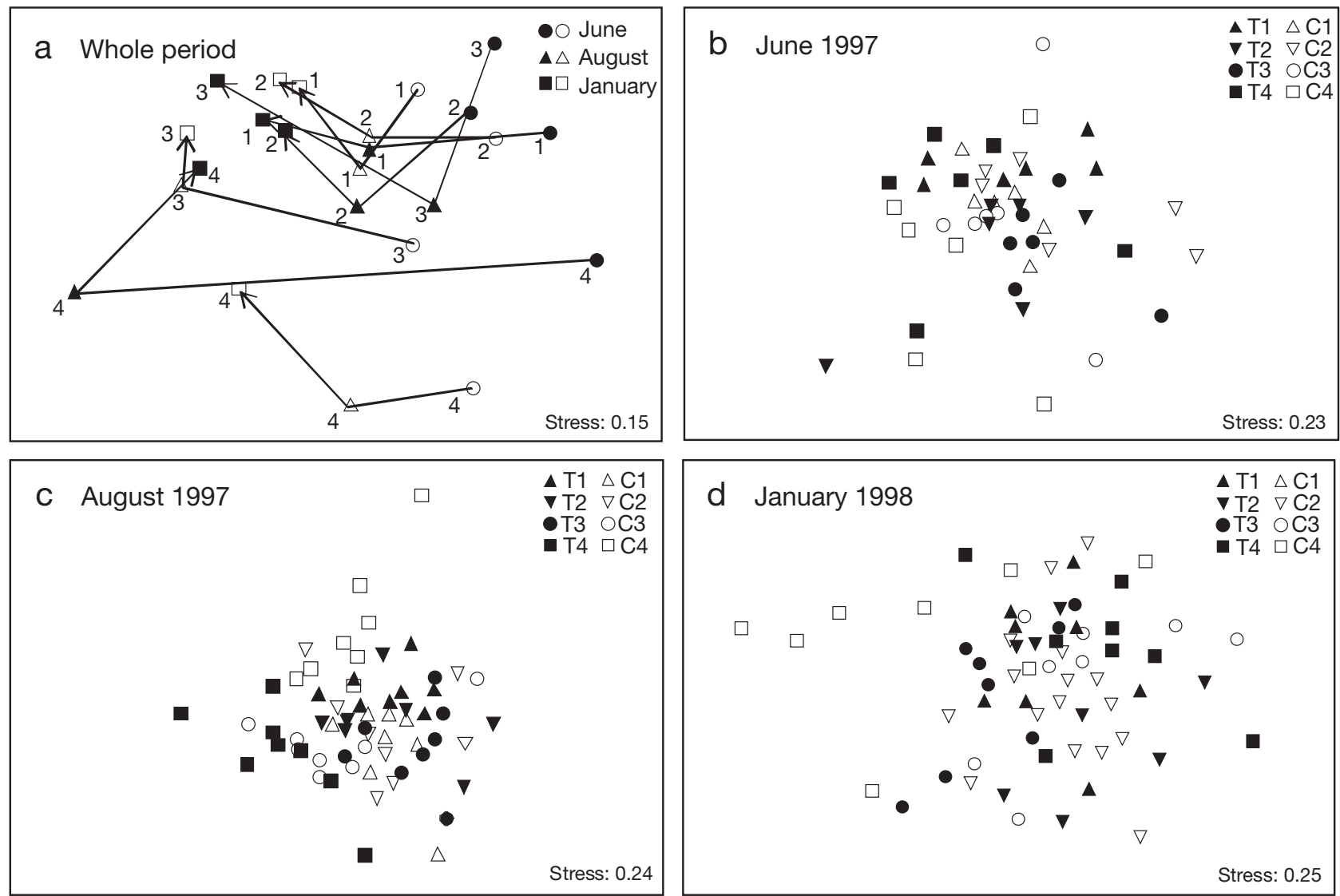

Fig. 2. Non-metric multidimensional scaling ordination of infauna (filled symbols: trawled plots; open symbols: controls) over: (a) the whole period (average abundance per plot, numbers identify plot number in each treatment) and on: (b to d) separate sampling occasions (June, August and January, respectively). Plot abbreviations as in Fig. 1 


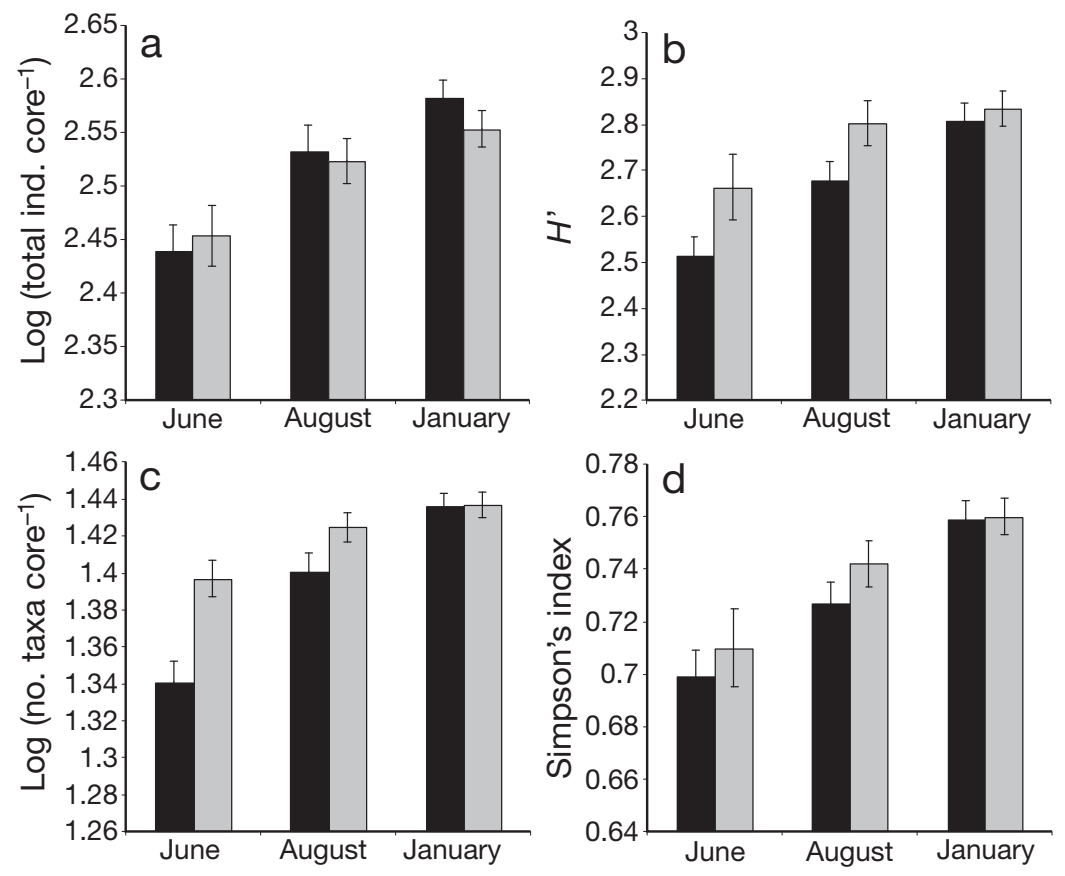

Fig. 3. Means $( \pm \mathrm{SE})$ in: (a) total number of individuals, (b) Shannon-Wiener diversity $\left(H^{\prime}\right)$, (c) number of taxa and (d) Simpson's reciprocal $1 / D$, in trawled (black bars) and untrawled (grey bars) plots
Another observed effect that appeared to be persistent during the whole experiment was the significant increase of the small-scale variability in species richness at trawled locations (Table 2). This increase in variability was not only significant but also substantial in magnitude (67\%). Finally, another observed effect of trawling was a significant interactive effect, $\operatorname{Tr} \times \mathrm{Ti}$, on the mean species richness (Table 2). Inspection of the means and SNK support the hypothesis that this is a temporary negative effect on species richness (Fig. 3; SNK of Tr $\times \mathrm{Ti}_{\text {; }}$ 'June': trawled < controls; 'August': trawled < controls and 'January': trawled $=$ controls). Further inspections of the means show that the initial impact caused the number of species to decrease by $12 \%$. Then, 2 mo later the difference was $5.4 \%$ and after 7 mo the difference was $\sim 0.2 \%$. The third index of diversity (Simpson) showed no significant effects of trawling.
(Table 2). No significant effects were observed on the total number of individuals (Table 2). The ShannonWiener index was significantly and persistently lower in the trawled areas compared to the controls. Despite a tendency for recovery during the experiment, the lack of a significant interaction $(\operatorname{Tr} \times \mathrm{Ti})$ indicated that the effect persisted throughout the experiment (Fig. 3). Overall, the Shannon-Wiener index decreased by approximately $3 \%$ in trawled areas $\left(\bar{x}_{\text {Control }}=2.78\right.$ and $\left.\bar{x}_{\text {Control }}=2.69\right)$. In all other community variables, the overall differences between trawled and control areas were $<2 \%$.

\section{Effects on abundances of individual taxa}

In contrast to the measures of diversity, there were no persistent long-term effects of trawling on abundances of individual taxa (Table 3). Furthermore, a significant short-term effect (i.e. Tr $\times$ Ti interaction) was found only for the bivalve Thyasira flexuosa, which was less abundant ( $70 \%$ ) in trawled plots immediately after trawling but more abundant in trawled plots at subsequent sampling times (34 and $15 \%$, respectively). Thus, significant long- or short-term effects on

Table 2. ANOVA model for total number of individuals and species and for Shannon-Wiener and Simpson's diversity measures. Significant results indicating impacts of trawling as persistent or temporary effects on the mean or effects on small-scale variability are shown in bold. F-tests were constructed using a priori error terms unless post hoc pooling was possible. Pooling terms are indicated by superscript: (a) $\mathrm{Pl}(\mathrm{Tr})$, (b) $\mathrm{Ti} \times \mathrm{Pl}(\mathrm{Tr})$, (c) $\mathrm{ST}(\mathrm{Tr}, \mathrm{Ti}, \mathrm{Pl})$, (d) residual

\begin{tabular}{|c|c|c|c|c|c|c|c|c|c|c|c|c|c|c|}
\hline \multirow{2}{*}{ Source } & \multirow[t]{2}{*}{$\mathrm{df}$} & \multicolumn{3}{|c|}{ Total no. of individuals } & \multicolumn{3}{|c|}{ Total no. of taxa } & \multicolumn{3}{|c|}{ —Shannon-Wiener- } & \multicolumn{3}{|c|}{ — Simpson's — } & \multirow[t]{2}{*}{ Error term } \\
\hline & & MS & $F$ & $\mathrm{p}$ & MS & $F$ & $\mathrm{p}$ & MS & $F$ & $\mathrm{p}$ & MS & $F$ & $\mathrm{p}$ & \\
\hline $\operatorname{Tr}$ & 1 & 0.02 & 0.22 & 0.659 & 0.04 & 2.06 & 0.20 & 0.65 & $4.75^{\mathrm{a}+\mathrm{b}+\mathrm{c}}$ & 0.03 & 0.003 & $0.58^{\mathrm{a}+\mathrm{c}}$ & 0.45 & $\mathrm{Pl}(\mathrm{Tr})$ \\
\hline $\mathrm{Ti}$ & 2 & 0.31 & 14.14 & 0.001 & 0.09 & 48 & 0.0001 & 1.35 & 10.43 & 0.002 & 0.07 & 9.65 & 0.003 & $\mathrm{Ti} \times \mathrm{Pl}(\mathrm{Tr})$ \\
\hline $\operatorname{Tr} \times \mathrm{Ti}$ & 2 & 0.002 & $0.06^{\mathrm{b}+\mathrm{c}}$ & 0.937 & 0.01 & 6.00 & 0.02 & 0.13 & $0.96^{\mathrm{a}+\mathrm{b}+\mathrm{c}}$ & 0.39 & 0.003 & 0.37 & 0.69 & $\mathrm{Ti} \times \operatorname{Pl}(\mathrm{Tr})$ \\
\hline $\mathrm{Pl}(\mathrm{Tr})$ & 6 & 0.07 & 2.21 & 0.045 & 0.02 & 4.67 & 0.002 & 0.09 & 0.64 & 0.69 & 0.001 & 0.18 & 0.98 & St $(\mathrm{Tr}, \mathrm{Ti}, \mathrm{Pl})$ \\
\hline $\mathrm{Ti} \times \operatorname{Pl}(\mathrm{Tr})$ & 12 & 0.02 & 0.7 & 0.746 & 0.002 & 0.54 & 0.89 & 0.13 & 0.93 & 0.51 & 0.008 & 1.47 & 0.14 & St $(\mathrm{Tr}, \mathrm{Ti}, \mathrm{Pl})$ \\
\hline $\mathrm{St}(\mathrm{Tr}, \mathrm{Ti}, \mathrm{Pl})$ & 152 & 0.03 & 1.45 & 0.010 & 0.005 & 1.24 & 0.09 & 0.14 & 1.2 & 0.12 & 0.005 & 1.31 & 0.04 & Residual \\
\hline Residual & 163 & 0.02 & & & 0.004 & & & 0.12 & & & 0.004 & & & \\
\hline \multicolumn{15}{|c|}{ Two-tailed F-tests of small-scale variability } \\
\hline Trawled & 79 & 0.02 & 1.048 & 0.418 & 0.005 & 1.67 & 0.01 & 0.09 & 1.39 & 0.07 & 0.004 & 1.25 & 0.16 & \\
\hline Controls & 84 & 0.02 & & & 0.003 & & & 0.13 & & & 0.005 & & & \\
\hline
\end{tabular}


Table 3. Results of ANOVA for the most abundant taxa. Significance was classified as ${ }^{*},{ }^{* *}$ and ${ }^{* * *}$ for $p<0.05,0.01$ and 0.001 , respectively. Non-significant results were categorised into 2 groups: NS* and NS for $0.05<p<0.10$ and p $>0.10$, respectively. Superscripts as in Table 2

\begin{tabular}{|c|c|c|c|c|c|c|c|}
\hline Taxon & $\operatorname{Tr}$ & $\mathrm{Ti}$ & $\operatorname{Tr} \times \mathrm{Ti}$ & $\mathrm{Pl}(\mathrm{Tr})$ & $\mathrm{Ti} \times \operatorname{Pl}(\mathrm{Tr})$ & $\mathrm{St}(\mathrm{Tr}, \mathrm{Ti}, \mathrm{Pl})$ & Two-tailed \\
\hline \multicolumn{8}{|l|}{ Polychaetes } \\
\hline Myriochele oculata ${ }^{\mathrm{b}+\mathrm{c}+\mathrm{d}}$ & NS & $* *$ & NS & $* *$ & NS & NS & $* *$ \\
\hline Paraonis sp. ${ }^{\mathrm{b}+\mathrm{c}+\mathrm{d}}$ & NS & $* * *$ & NS & $* *$ & NS & NS & NS \\
\hline Eteone longa ${ }^{\mathrm{b}+\mathrm{c}}$ & NS & $\mathrm{NS}^{*}$ & NS & $* * *$ & NS & $\mathrm{NS}^{*}$ & NS \\
\hline Scoloplos armiger ${ }^{\mathrm{c}+\mathrm{d}}$ & NS & $* * *$ & NS & $* * *$ & NS & $*$ & NS \\
\hline Cossura longocirrata & NS & $* * *$ & NS & $* * *$ & $* * *$ & NS & NS \\
\hline Pholoe minuta & NS & ** & NS & ** & $\mathrm{NS}^{*}$ & NS & NS \\
\hline Sternaspis scutata $^{\mathrm{b}+\mathrm{c}}$ & NS & NS & NS & $* *$ & NS & ${ }^{* *}$ & NS \\
\hline Scalibregma inflatum & NS & $* * *$ & NS & *** & ** & $\mathrm{NS}^{*}$ & NS \\
\hline Maldane sarsi $^{\mathrm{b}+\mathrm{c}+\mathrm{d}}$ & NS & * & NS & *** & NS & NS & NS \\
\hline Brada villosa ${ }^{\mathrm{b}+\mathrm{c}}$ & NS & $* * *$ & NS & $* *$ & NS & NS & NS \\
\hline Praxillella spp. & NS & ${ }^{* * *}$ & NS & $* * *$ & NS & NS & NS \\
\hline Spio sp. ${ }^{\mathrm{b}+\mathrm{c}}$ & NS & $* * *$ & NS & NS & NS & * & NS \\
\hline Schistomeringos nigridentata ${ }^{\mathrm{c}+\mathrm{d}}$ & NS & $* * *$ & NS & $* *$ & $*$ & NS & NS \\
\hline Chaetozone setosa ${ }^{\mathrm{a}+\mathrm{c}}$ & NS & ${ }^{* *}$ & NS & NS & $\mathrm{NS}^{*}$ & NS & NS \\
\hline Syllidae ${ }^{c+d}$ & NS & $* * *$ & NS & $* *$ & $\mathrm{NS}^{*}$ & NS & NS \\
\hline Goniada maculata ${ }^{\mathrm{c}+\mathrm{d}}$ & NS & NS & NS & $* * *$ & * & NS & NS \\
\hline 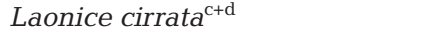 & NS & ${ }^{* * *}$ & NS & NS & $\mathrm{NS}^{*}$ & NS & NS \\
\hline Lumbrineris fragilis $^{\mathrm{c+d}}$ & NS & NS & NS & **** & NS & NS & NS \\
\hline Ophelina acuminata & NS & ${ }^{* *}$ & NS & **** & $* * *$ & NS & NS \\
\hline Aricidea sp. ${ }^{\mathrm{b}+\mathrm{c}+\mathrm{d}}$ & NS & ${ }^{* *}$ & NS & $\mathrm{NS}^{*}$ & NS & NS & NS \\
\hline Apistobranchus tullbergi & NS & $* * *$ & NS & **** & NS & * & NS \\
\hline Terebellides stroemi & NS & $* * *$ & NS & ** & NS & ** & NS \\
\hline Heteromastus filiformis $^{\mathrm{c}+\mathrm{d}}$ & NS & $* * *$ & NS & NS & $*$ & NS & NS \\
\hline \multicolumn{8}{|l|}{ Crustaceans } \\
\hline Isopoda $^{\mathrm{a}+\mathrm{c}+\mathrm{d}}$ & $\mathrm{NS}^{*}$ & * & NS & NS & NS & NS & NS \\
\hline Amphipoda ${ }^{\mathrm{a}+\mathrm{c}+\mathrm{d}}$ & NS & NS & NS & NS & NS & $* *$ & NS \\
\hline \multicolumn{8}{|l|}{ Molluscs } \\
\hline Abra spp. & NS & $* * *$ & NS & $* * *$ & *** & ** & NS \\
\hline Macoma calcarea ${ }^{\mathrm{b}+\mathrm{c}}$ & NS & $*$ & NS & $* * *$ & NS & NS & NS \\
\hline Thracia spp. & NS & NS & NS & $* * *$ & $\mathrm{NS}^{*}$ & NS & NS \\
\hline Arctica islandica ${ }^{\mathrm{c}+\mathrm{d}}$ & NS & $\mathrm{NS}^{*}$ & NS & $* * *$ & $* * *$ & NS & NS \\
\hline Thyasira flexuosa $^{\mathrm{b}+\mathrm{c}}$ & NS & $* * *$ & $* *$ & $* *$ & NS & NS & * \\
\hline Mytilidae $\mathrm{e}^{\mathrm{b}+\mathrm{c}+\mathrm{d}}$ & NS & $* *$ & NS & NS & NS & NS & $* *$ \\
\hline \multicolumn{8}{|l|}{ Echinoderms } \\
\hline Ophiura sp..$^{\mathrm{a}+\mathrm{b}+\mathrm{c}+\mathrm{d}}$ & NS & ** & NS & NS & NS & NS & NS \\
\hline
\end{tabular}

average abundance were found for only 1 out of 32 investigated taxa.

Similarly, the 2-tailed tests that examined changes in small-scale spatial variability showed few effects (Table 3). Interestingly, the abundance of Thyasira flexuosa again appeared to be significantly affected, with the small-scale variability being $\sim 35 \%$ smaller in trawled areas compared to the controls. For mytilid bivalves, however, the small-scale variability in abundance was $>2$-fold greater in trawled areas, resulting in a significant 2-tailed test.

In contrast to the small number of significant effects of trawling, abundances of all taxa varied significantly in time and/or space (Table 3). Abundance of most taxa differed significantly among plots within treatments, indicating that differences among plots were due to factors other than trawling or that responses of benthic organisms to fishing disturbances were not consistent among plots. Relatively few taxa (Cossura longocirrata, Scalibregma inflatum, Schistomeringos nigridentata, Goniada maculata, Ophelina acuminata, Heteromastus filiformis, Abra spp. and Arctica islandica) showed significant interactive variability $(\mathrm{Ti} \times \mathrm{Pl}(\mathrm{Tr}))$, i.e. plots within treatments changed similarly among times. Further, there were few instances (Scoloplos armiger, Apistobranchus tullbergi, Terebellides stroemi, Sternaspis scutata, Spio sp., amphipods and Abra spp.) of significant variability among stations within plots (St[Tr, Ti, Pl]).

\section{Power analyses}

The power analyses of community variables revealed that smaller proportional changes are required to detect effects on any of the measures of diversity 
compared to the changes needed to detect effects on total abundance (Fig. 4). If there were persistent effects on diversity these would have needed to be on the order of 3 to $5 \%$ to be reliably detected using Shannon-Wiener and Simpson's indices. For species richness and total abundance, the corresponding values were 15 and $25 \%$, respectively. Note that the observed differences for these 2 indices were $<2 \%$.

The MDES values of short-term effects were generally larger than those of any persistent effect (Fig. 4). To reliably detect changes in richness and ShannonWiener indices these need to be between 5 and $10 \%$, but between 10 and $15 \%$ for the Simpson index, while the corresponding figure for total abundance is again $\sim 25 \%$. Although there are slight differences in sensitivity among the different measures of diversity, the overall impression is that the changes needed to detect effects are smaller for these 3 measures of diversity than for abundance.

The apparent difficulties associated with detecting effects on abundance were highlighted by further analyses of the MDES for abundance of the 3 most abundant taxa (Myriochele oculata, Abra spp. and Paraonis sp.) and the 3 least abundant taxa subjected to detailed ANOVA (Ophiura sp., Lumbrineris fragilis
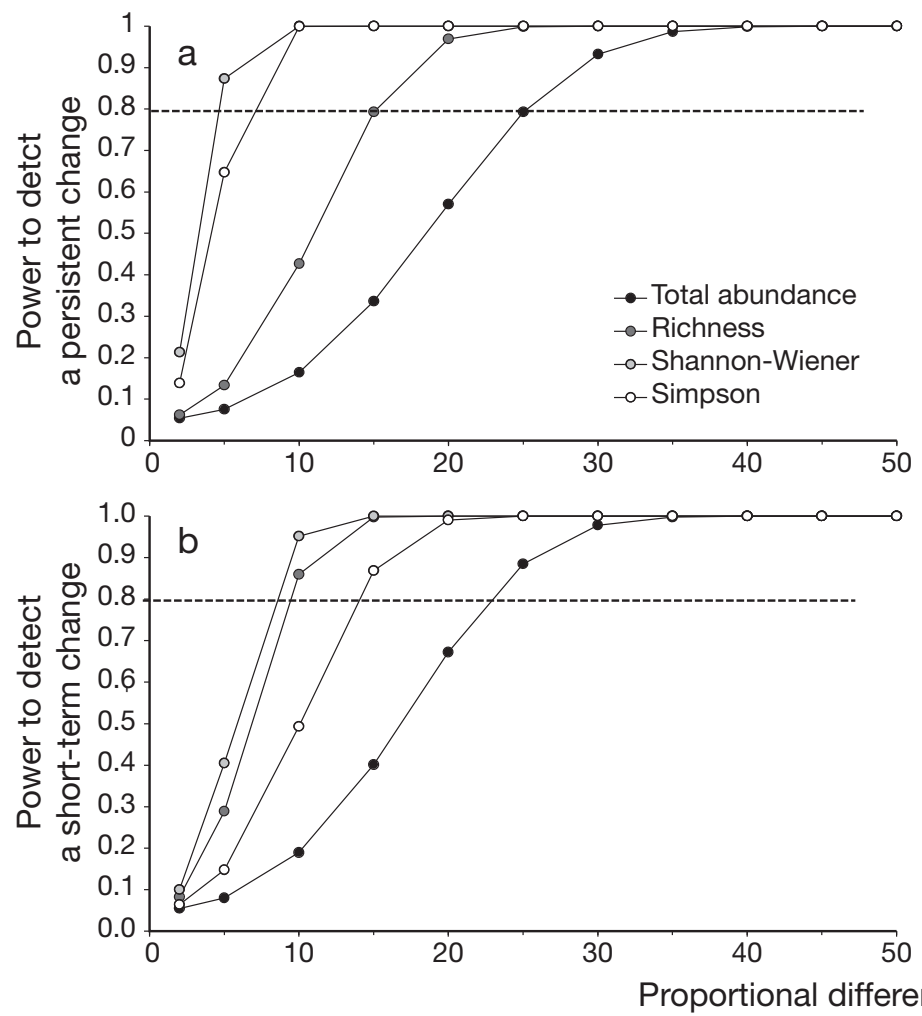

Fig. 4. Statistical power as a function of proportional difference between trawled and control areas: evaluated for persistent effects $(a, c)$ and short-term effects $(b, d)$ and for total abundance, species richness, Shannon-Wiener index and Simpson's index $(a, b)$ and the 3 most abundant taxa (Myriochele oculata, Abra spp. and Paraonis sp.) and the 3 least common taxa (Ophiura sp., Lumbrineris fragilis and Aricidea sp.) that could be analysed statistically (c,d). The dotted lines refer to $80 \%$ statistical power

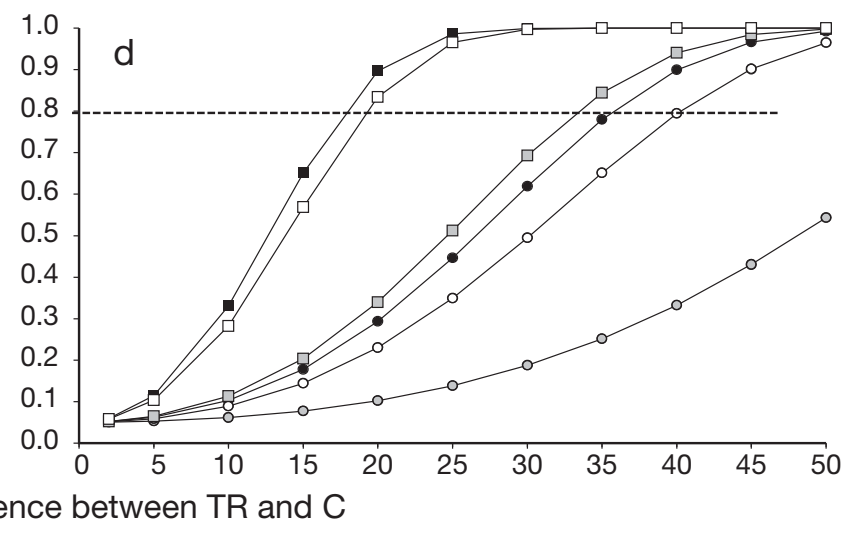

and Aricidea sp.). These analyses showed that to reliably detect impacts of trawling on abundant taxa, changes in abundance generally need to be $>35 \%$, both for tests of persistent and short-term effects (Fig. 4c,d). Interestingly, the MDES values of the 3 rarer taxa were consistently smaller. Persistent effects could be reliably detected at changes of 10 to $30 \%$, while the corresponding figures for short-term effects were 15 to $35 \%$.

\section{Qualitative changes of taxa}

Even if mean and small-scale variability values in the abundance of very few individual taxa were significantly affected by trawling, it is possible that differences between trawled and control areas are qualitatively consistent. To test this proposition, simple sign (binomial) tests were performed. These analyses showed that in June, $79 \%$ of the taxa had lower mean abundance in trawled plots compared to untrawled plots. This proportion is significantly greater than what can be expected by chance $(p<0.001)$, and these differences were mainly driven by rarer taxa (Fig. 5). About $50 \%$ of all taxa with average abundances of $<1$ individ-

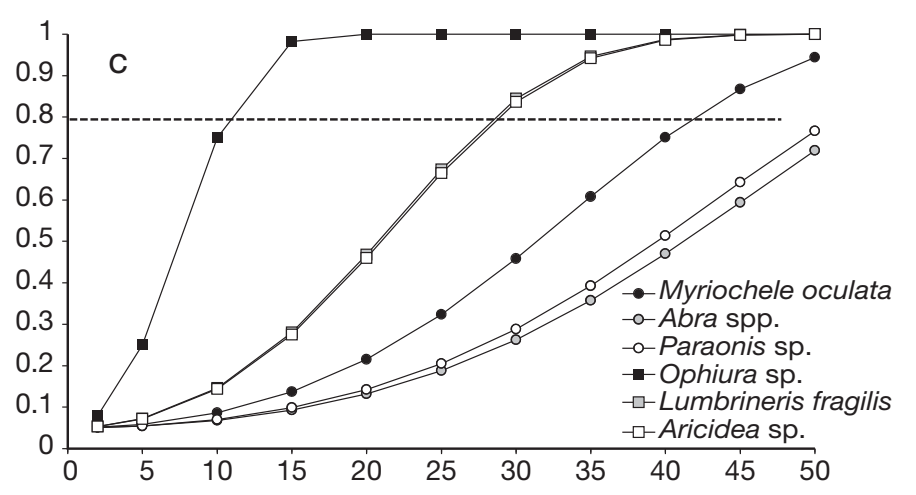



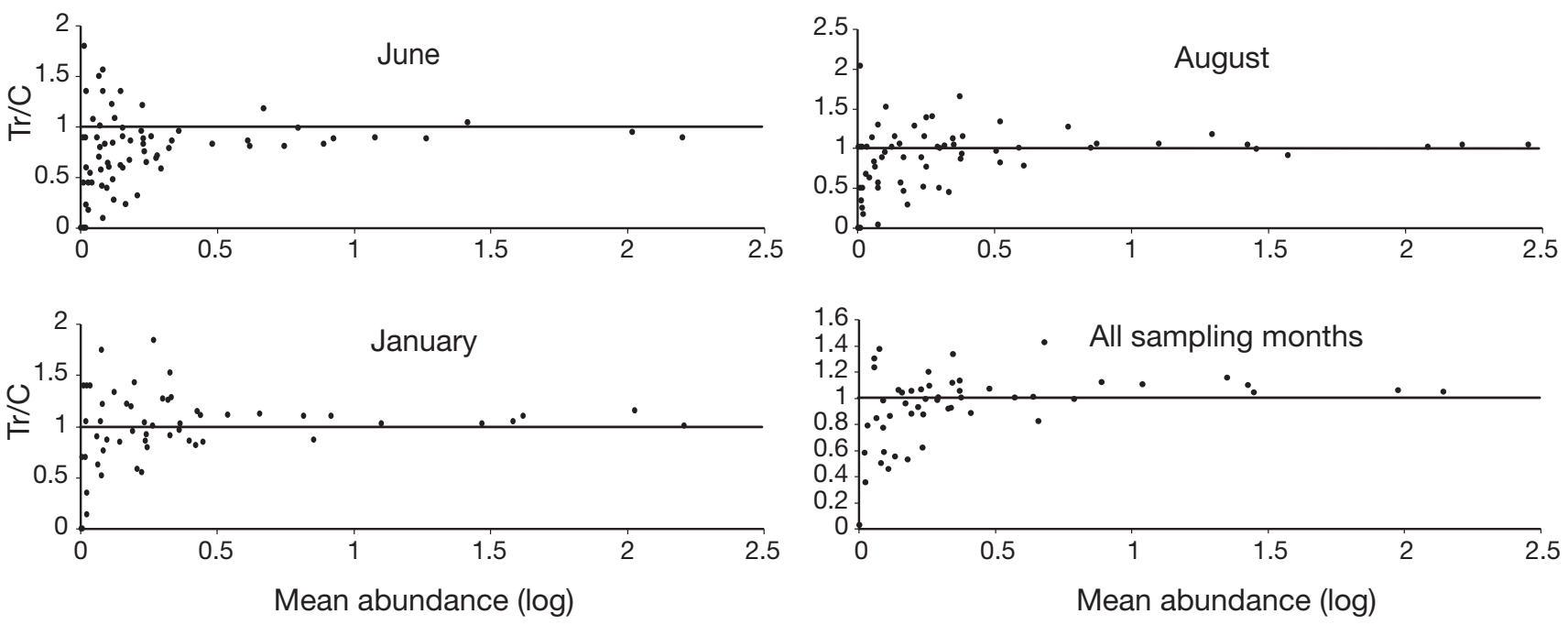

Fig. 5. The ratio of mean abundance of individual taxa in trawled and untrawled plots $(\mathrm{Tr} / \mathrm{C})$ in different sampling periods as a function of overall mean abundance

ual sample $\mathrm{e}^{-1}$ declined by $30 \%$, and $61.5 \%$ of all taxa represented by 1 to 5 ind. on average declined by $>20 \%$. In August and January, the proportions of taxa found in lower abundance in trawled plots were 46 and $50 \%$, respectively. For the whole experiment the proportion was $50 \%$. These differences were not significantly different from chance alone ( $p>0.05$; Fig. 5).

\section{DISCUSSION}

Type, size and duration of impacts

The aim of the present study was to test hypotheses about temporary and persistent effects of otter trawling in a previously undisturbed area at intensities that are representative of those in heavily trawled areas around Iceland (Ragnarsson \& Steingrímsson 2003). Our results show that trawling caused short-term and persistent effects on average and small-scale variability in diversity of infauna, while effects on abundances of individual taxa were difficult to detect. Using appropriate estimates of variability we also demonstrated that effect sizes of $>20 \%$ change are necessary to reliably detect short- and long-term effects on abundance of individual taxa, while changes of $<5 \%$ were often sufficient for measures of diversity. Nevertheless, despite the difficulties in detecting the effects on abundance of individual taxa, we also demonstrated that there was a significant tendency for benthic taxa in general to have lower abundances at fished compared to unfished locations immediately after trawling.

The observed effects on diversity were consistently largest immediately after the experimental treatment.
Nevertheless, the fact that the effect on mean richness was detected as a significant interaction between time and treatment, while that effect on the ShannonWiener measure was detected as a significant effect of treatment, indicates that the persistence of observed effects differed among measures of diversity. The species richness decreased by $12 \%$ immediately after trawling, whilst after 7 mo the difference was $0.2 \%$. The corresponding figures for the Shannon-Wiener measure were 5.4 and $0.9 \%$. One reasonable interpretation of this result is that taxa that are initially removed from the area return relatively quickly, while the establishment of natural assemblages in terms of relative abundances and ecological associations takes longer time. This interpretation is supported by the observation of qualitative effects mainly involving decreases in abundances of rare taxa immediately after trawling. Among these were the relatively largebodied maldanid and terebellid taxa, which have previously been reported to be sensitive to fishing (Kaiser \& Spencer 1996, Tuck et al. 1998, Sanchez et al. 2000, Jennings et al. 2001, Duplisea et al. 2002, Hiddink et al. 2006). Although these differences were subtle, they may nevertheless have accounted for the initial effects on richness. Similarly, Kaiser \& Spencer (1996) and Kenchington et al. (2001) reported abundance declines in most taxa following trawling. These were generally more pronounced for rarer taxa, but significant differences for individual taxa were rarely attained. Hansson et al. (2000) reported that, while $61 \%$ of all taxa recorded in their study were found at lower abundance in trawled plots, significance was only attained for 1 individual taxon, and there was no obvious relationship between the size of organisms and the size of impacts. 


\section{Impacts on spatial variability}

The variability in species richness was augmented at trawled plots following trawling, but these effects did not last long. Lindegarth et al. (2000a) reported increased temporal and spatial variability in the structure of benthic communities at trawled sites. The reason for increased variance may have been due to disproportionate fishing impacts within the trawl swath. For soft bottoms at least, the otter-boards are considered to have more impact per unit area compared to the ground-rope, mainly because they penetrate deeper into the seabed (e.g. Gilkinson et al. 1998). In our study, the surface area swept by the boards in a single tow was small (0.8 to $1.5 \mathrm{~m}$ in width) compared to that of the ground-rope $(\sim 13 \mathrm{~m})$. This means that in a single tow, $\sim 32 \%$ of the total tow width (distance between otter-boards; $\sim 40 \mathrm{~m}$ ) was swept with the ground-rope and $\sim 2$ to $4 \%$ was swept with the otter-boards. The probability of retrieving a sample from a otter-board track in our study within a trawl swath of $100 \mathrm{~m}$ that had been towed 10 times could be somewhere between 5 and $15 \%$. If invertebrate densities declined markedly only in those areas swept with the otter-boards, it would be unlikely to detect any overall decline at the scale of the trawl swath, as the vast majority of samples would be obtained outside the otter-board tracks. Nevertheless, such disproportionate impact within the trawl swath may result in overall reduction in species richness and those diversity measures that are influenced by the loss of the rarer taxa (like the Shannon-Wiener), while augmenting the spatial variability.

\section{Consistency with previous studies}

To further put our results into the context of previous work on impacts of otter trawling in muddy areas, we compared the size and persistence of impacts to those reported in the meta-analysis by Kaiser et al. (2006). To achieve this, we calculated the average difference between trawled and control plots at individual times and for all taxa used in ANOVA analyses (using the equation for response measure provided by Kaiser et al. 2006), and compared it with metaanalysis outputs (see Figs. $2 \& 3$ in their paper) for studies carried out in muddy habitats (Fig. 6). Our study revealed that immediately after trawling, the abundances of individual taxa were on average $16 \%$ lower in trawled areas compared to undisturbed areas, while the corresponding figure for the metaanalysis was 28\% (see Fig. 2 in Kaiser et al. 2006). The results in our study suggest that the differences can be regarded as being significant as the confi-

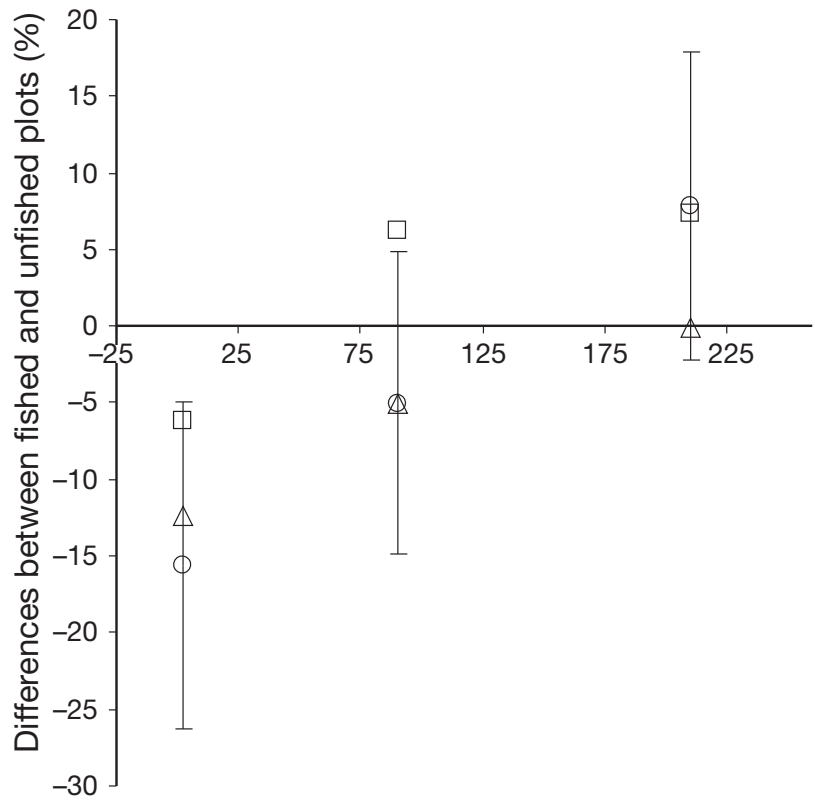

Time from trawling (d)

Fig. 6. Responses (mean $\pm 2 \mathrm{SD}$ ) of benthic taxa (O), total number of individuals $(\square)$ and species $(\Delta)$ to otter trawling

dence limits do not include zero. Furthermore, the fact that the error bars in the present study overlap largely with those of the meta-analysis suggests that our results, in terms of initial impacts, are highly consistent with previous results using the same type of gear in similar environments. On the other hand, our results are not entirely consistent with previous studies with respect to patterns of recovery (see Fig. 3 in Kaiser et al. 2006). Although detailed comparisons of recovery patterns for the 2 data sets are difficult due to differences in times of sampling, there appears to be consistency among studies in terms of initial (1 to $2 \mathrm{mo}$ ) recovery of mean abundances. Beyond a few months, however, it seems that most studies have observed increased abundances of individual taxa in trawled areas. Such a response could be attributed to colonisation of opportunistic taxa benefiting from the changed environment as a result of fishing disturbance (de Juan et al. 2007). In our study, the average change in the abundance of individual taxa showed no signs of long-term increases in trawled areas. However, there was a tendency for increased total abundances in trawled areas after 3 and 7 mo (Fig. 6), but, because our study can only provide a point estimate of change in total abundance, it is difficult to assess the significance of this result. Unfortunately, Kaiser et al. (2006) did not provide comparable data on longer term effects of otter trawling in muddy habitats with respect to total number of individuals or 
species richness (Fig. 6). Nevertheless, the initial impacts on both total abundance and richness in our study (Fig. 6) are in many respects similar to those which have been observed in previous studies using otter trawls in similar environments (e.g. Tuck et al. 1998, Ball et al. 2000, Hansson et al. 2000, Lindegarth et al. 2000a, Sanchez et al. 2000, Drabsch et al. 2001, Kenchington et al. 2001, Kutti et al. 2005).

It is difficult to evaluate the extent to which the magnitude and persistence of initial impacts is representative of a wider set of benthic assemblages and types of fishing gear. Previous studies have highlighted fishing gear type, seabed characteristics, frequency of natural disturbances and water depth to be the most important factors (e.g. Kaiser et al. 2002). Other studies have shown that trawling can modify the overall functioning of benthic communities, such as by altering the relative composition of functional groups (de Juan et al. 2007) and/or the biogeochemical environment (Allen \& Clarke 2007). Hiddink et al. (2006) predicted, by using a modelling approach, that the effects of trawling were less strong in areas where shear stress is high and the bottom is of mud or muddy sands. The shallow depth at our study site does indicate that suspension and transport of sediments is likely to be considerable during storms, and the area can be regarded as a dynamic environment (Churchill 1989). The infauna, dominated by small-bodied $(<1 \mathrm{~cm})$, mobile, deposit-feeding taxa, is probably easily suspended during storms (e.g. Posey et al. 1996), and is therefore likely to be adapted to the sediment disturbance caused by the experimental trawling in our study. This view of relatively resilient ecological assemblages at the experimental site is also supported by the uni- and multivariate analyses that show substantial temporal variability, often across the whole study area, but sometimes differently among plots within the area.

The dynamic nature of the environment at the study site indicates that recolonisation of animals (both probably active and passive) is likely to be rapid. Our estimates on recovery rates are fully consistent with those observed in other manipulative trawl impact studies (Kaiser et al. 2006). Recovery in our study, as for most other small-scale trawl impact studies carried out on soft sediments, is likely to be rapid due to the proximity of undisturbed sea beds, where $\sim 90 \%$ of the overall study area was undisturbed. However, at the scale of the commercial fishery (e.g. Thrush et al. 1998), the much larger size of areas impacted by fishing implies that the distances to undisturbed areas are greater and, thus, slower rates of recolonisation would be expected. Similarly, recovery patterns in our study may differ from those in the real fishery, where the benthic community can be subjected to fishing pressure over longer periods of time (Kaiser et al. 2002).

\section{Indicators of impacts}

Findings from our study show that trawling caused significant negative impacts on several aspects of diversity of infauna, while significant effects on abundances of dominant taxa and on multivariate community structure were practically absent. Because none of these variables are strictly independent, this result may appear contradictory. Clearly, different taxa vary in their sensitivity to physical disturbance, but it is logically inconsistent to propose that species richness and Shannon-Wiener's index may be affected negatively by trawling without any negative effects on individual taxa. Nevertheless, we showed that taxa were in most cases negatively affected by trawling, but it was generally difficult to identify significant effects on particular taxa. The most likely explanation of why significant effects were detected for measures of diversity, but not for abundance data, is that there were differences in statistical power between the 2 classes of variables (e.g. Osenberg et al. 1994, Mapstone 1995). These differences can, in turn, be explained either by differences in effect sizes or in error variability (i.e. denominator MS) in the tests critically evaluating hypotheses regarding the impacts of trawling. The analyses presented here suggest that the main cause is that the error variability was generally larger for measures of abundance compared to those of diversity. The rationale behind this conclusion is that the power analyses showed that the minimum detectable effect size was consistently larger for measures of abundance, both for persistent and short-term effects. Second, inspections of means in trawled and control plots showed that the observed effect sizes for measures of diversity were not larger than those of abundances, and in fact these were often smaller. It is worth emphasising that another important issue to do with statistical power is that the number of replicate units and error degrees of freedom did not differ between the 2 types of variables and, therefore, cannot explain why measures of diversity appeared to be more powerful. Furthermore, it appears unlikely that alternative designs, involving more replicate plots, stations, or samples would have improved the statistical power substantially. This is because most tests were done using pooled error mean squares in such a way that many hypotheses about the effects of trawling could be tested using $>150 \mathrm{df}$ (maximum $333 \mathrm{df}$ ) in the denominator. By all reasonable standards for experimental ecology this must be considered a sufficient degree of replication (Underwood 1997, Quinn \& Keough 2002). Exceptions to this, however, are the multivariate tests using PERMANOVA. For example, the tests for short-term effects were done with only $12 \mathrm{df}$ in the denominator mean square. This may explain the lack of significant multivariate effects 
that otherwise are considered particularly powerful for the detection of environmental impacts (e.g. Gray et al. 1990, Clarke 1993, Anderson \& Thompson 2004).

In our study, measures of diversity appeared to be more sensitive to environmental impacts than abundances of individual taxa in terms of the proportional effects that can be reliably detected. In general, studies on soft-sediment macrofauna that have reported impacts of trawling on species diversity have also shown effects on abundances and/or community structure (e.g. Kaiser \& Spencer 1996, Tuck et al. 1998, Smith et al. 2000). Others have reported effects of trawling on abundances and community structure, but not on diversity (e.g. Hansson et al. 2000). Nevertheless, in consistency with the observations presented here, previous analyses of statistical power of different community metrics in aquatic environments suggest that it is usually possible to reliably detect smaller impacts on measures related to species diversity, such as richness, evenness and environmental quality indices, compared to measures of abundance (e.g. Pratt \& Bowers 1992, Johnson 1998, Sandin \& Johnson 2000, Schratzberger et al. 2002). This does not necessarily mean that tests of hypotheses about effects on diversity are more powerful than those on abundance, but rather that diversity estimates may be less variable. The actual power is also determined by the strength of mechanistic coupling between trawling and the response variable (i.e. the true effect size). Clearly some taxa, such as epibenthic megafauna (e.g. Wassenberg et al. 2002), may be particularly vulnerable to trawling due to their specific morphologies and lifehistory characteristics. Due to the expected large effect size, tests of impacts on such taxa are likely to be powerful despite large error variability. Such taxa were, however, largely missing or rare in our study. The taxa that showed signs of impacts (in small-scale variability and interaction between time and treatment), i.e. Myriochele oculata, Thyasira flexuosa and Mytilidae, do indeed live inside tubes and calcareous shells that may be vulnerable to physical disturbance, but so are many of the taxa that were not significantly affected. Thus, in the assemblages present in our experimental plots, such life-history characteristics were not strong predictors of impact. Instead, one general lesson from this study is that impacts on abundances of individual taxa are unlikely to be detected with a high probability unless the effect size is large.

Although the present study examined effects of trawling with rigorous experimental design (4 replicate plots, 3 sampling occasions and a total sampling effort of 340 samples), weak or no effects on abundance or on multivariate structure were detected. However, findings from our study indicate that the effects of trawling in this particular environment were subtle and mostly did not last long. They were detected as changes in diversity, small-scale variability and declines in abundance of most taxa. Power analyses similarly revealed that smaller statistical power was needed to detect changes in diversity than in abundance. Our findings indicate that these patterns are to a large extent driven by loss of the rarer taxa. This conclusion is further supported by a power analysis showing that the statistical power to detect changes in means of the 3 rarest taxa (that could be statistically analysed) was greater than the power to detect changes in the means of the 3 dominant taxa. Similarly to most other manipulative experiments on trawling, our study was designed to detect effects of a single intense disturbance. The extent to which these impacts are representative of the size and persistence of continuous, low-intensity disturbance represents an important challenge to future studies.

Acknowledgements. S.A.R. is especially grateful to S. A. Steingrímsson for his help in the planning of this project, comments on the earlier drafts of this manuscript and assistance during fieldwork. The manuscript was improved by the comments of E. Kenchington and E. Guijarro Garcia. S.A.R. also thanks H. Björnsson for preparing S-plus scripts and G. V. Helgason for reviewing the identification of polychaetes. Thanks are due to the crews of the research vessels 'Árni Friðriksson' and 'Dröfn' for their assistance during sampling and to P. Ásgeirsson and H. Skarphéðinsdóttir for their hard fieldwork. S.A.R. also thanks the staff at the Sandgerdi Marine Centre and R. Ólafsdóttir for sample analysis. This project was partly supported by funds from the Icelandic centre for research (RANNIS). Financial support was provided to M.L. from the Swedish research council for environment, agricultural sciences and spatial planning (FORMAS) through Contract 217-2006-357.

\section{LITERATURE CITED}

Allen JI, Clarke KR (2007) Effects of demersal trawling on ecosystem functioning in the North Sea: a modelling study. Mar Ecol Prog Ser 336:63-75

Anderson MJ (2001) A new method for non-parametric multivariate analysis of variance. Austral Ecol 26:32-46

Anderson MJ, Thompson AA (2004) Multivariate control charts for ecological and environmental monitoring. Ecol Appl 14:1921-1935

Bale AJ, Kenny AJ (2005) Sediment analysis and seabed characterisation. In: Eleftheriou A, McIntyre A (eds) Methods for the study of marine benthos, 3rd edn. Blackwell Science, Oxford, p 43-87

Ball BJ, Fox G, Munday BW (2000) Long- and short-term consequences of a Nephrops trawl fishery on the benthos and environment of the Irish Sea. ICES J Mar Sci 57: $1315-1320$

Churchill JH (1989) The effects of commercial trawling on sediment resuspension and transport over the Middle Atlantic Bight continental shelf. Cont Shelf Res 9:841-864

Clarke KR (1993) Non-parametric multivariate analyses of changes in community structure. Aust J Ecol 18:117-143

Clarke KR, Warwick RM (1994) Change in marine communities: an approach to statistical analysis and interpretation. Plymouth Marine Laboratory, Plymouth 
Collie JS, Escanero GA, Valentine PC (1997) Effects of bottom fishing on the benthic megafauna of Georges Bank. Mar Ecol Prog Ser 155:159-172

Costello MJ, McCrea M, Freiwald A, Lundälv T and others (2005) Role of cold-water Lophelia pertusa coral reefs as fish habitat in the NE Atlantic. In: Freiwald A, Roberts JM (eds) Cold-water corals and ecosystems. Springer-Verlag, Berlin, p 771-805

Currie DR, Parry GD (1996) Effects of scallop dredging on a soft sediment community: a large-scale experimental study. Mar Ecol Prog Ser 134:131-150

> de Juan S, Thrush SF, Demestre M (2007) Functional changes as indicators of trawling disturbance on a benthic community located in a fishing ground (NW Mediterranean Sea). Mar Ecol Prog Ser 334:117-129

$>$ Drabsch SL, Tanner JE, Connell SD (2001) Limited infaunal response to experimental trawling in previously untrawled areas. ICES J Mar Sci 58:1261-1271

> Duplisea DE, Jennings S, Warr KJ, Dinmore TA (2002) A size-based model of the impacts of bottom trawling on benthic community structure. Can J Fish Aquat Sci 59: 1785-1795

Fosså JH, Mortensen PB, Furevik DM (2002) The deep-water coral Lophelia pertusa in Norwegian waters: distribution and fishery impacts. Hydrobiologia 471:1-12

Gilkinson K, Paulin M, Hurley S, Schwinghamer P (1998) Impacts of trawl door scouring on infaunal bivalves: results of a physical trawl door model/dense sand interaction. J Exp Mar Biol Ecol 224:291-312

> Gray JS, Clarke KR, Warwick RM, Hobbs G (1990) Detection of initial effects of pollution on marine benthos: an example from the Ekofisk and Eldfisk oilfields, North Sea. Mar Ecol Prog Ser 66:285-299

Gray JS, Dayton P, Thrush S, Kaiser MJ (2006) On effects of trawling, benthos and sampling design. Mar Pollut Bull 52:840-843

> Gray JS, Dayton P, Thrush S, Kaiser MJ (2007) Fishing for facts on the environmental effects of trawling and dredge fisheries: reply to Løkkeborg. Mar Pollut Bull 54:497-500

Hansson M, Lindegarth M, Valentinsson D, Ulmestrand M (2000) Effects of shrimp-trawling on abundance of benthic macrofauna in Gullmarsfjorden, Sweden. Mar Ecol Prog Ser 198:191-201

Henderson CR (1953) Estimation of variance and covariance components. Biometrics 9:226-252

> Hiddink JG, Jennings S, Kaiser MJ, Queirós AM, Duplisea DE, Piet GJ (2006) Cumulative impacts of seabed trawl disturbance on benthic biomass, production, and species richness in different habitats. Can J Fish Aquat Sci 63: 721-736

Hurlbert SH (1984) Pseudoreplication and the design of ecological field experiments. Ecol Monogr 54:187-211

Jennings S, Dinmore TA, Duplisea DE, Warr KJ, Lancaster JE (2001) Trawling disturbance can modify benthic production processes. J Anim Ecol 70:459-475

Johnson RK (1998) Spatiotemporal variability of temperate lake macroinvertebrate communities: detection of impact. Ecol Appl 8:61-70

Kaiser MJ, Spencer BE (1996) The effects of beam-trawl disturbance on infaunal communities in different habitats. J Anim Ecol 65:348-358

Kaiser MJ, Collie JS, Hall SJ, Jennings S, Poiner IR (2002) Modification of marine habitats by trawling activities: prognosis and solutions. Fish Fish 3:1-24

Kaiser MJ, Clarke KR, Hinz H, Austen MCV, Somerfield PJ, Karakassis I (2006) Global analysis of response and recovery of benthic biota to fishing. Mar Ecol Prog Ser 311:1-14
Kenchington ELR, Prena J, Gilkinson KD, Gordon Jr DC and others (2001) Effects of experimental otter trawling on the macrofauna of a sandy bottom ecosystem on the Grand Banks of Newfoundland. Can J Fish Aquat Sci 58: 1043-1057

Krost P, Bernhard M, Werner F, Hukriede W (1990) Otter trawl tracks in Kiel Bay (western Baltic) mapped by sidescan sonar. Meeresforschung 32:344-353

Kutti T, Høisæter T, Rapp HT, Humborstad OB, Løkkeborg S, Nøttestad L (2005) Immediate effects of experimental otter trawling on a sub-arctic benthic assemblage inside Bear Islands fishery protection zone in the Barents Sea. In: Barnes PW, Thomas JP (eds) Benthic habitats and the effects of fishing. Am Fish Soc Symp 41:519-528

> Lindegarth M, Valentinsson D, Hansson M, Ulmestrand M (2000a) Effects of trawling disturbances on temporal and spatial structure of benthic soft-sediment assemblages in Gullmarsfjorden, Sweden. ICES J Mar Sci 57:1369-1376

Lindegarth M, Valentinsson D, Hansson M, Ulmestrand M (2000b) Interpreting large-scale experiments on effects of trawling on benthic fauna: an empirical test of the spatial confounding in experiments without replicated control and trawled areas. J Exp Mar Biol Ecol 245:155-169

Løkkeborg S (2007) Insufficient understanding of benthic impacts of trawling is due to methodological deficiencies - a reply to Gray et al. (2006). Mar Pollut Bull 54: 494-496

> Mapstone BD (1995) Scalable decision rules for environmental impact studies: effect size, type I and type II errors. Ecol Appl 5:401-410

McArdle BH, Anderson MJ (2001) Fitting multivariate models to community data: a comment on distance-based redundancy analysis. Ecology 82:290-297

Osenberg CW, Schmitt RJ, Holbrook SJ, Abu-Saba KE, Flegal AR (1994) Detection of environmental impacts: natural variability, effect size, and power analysis. Ecol Appl 4: $16-30$

Posey M, Lindberg W, Alphin T, Vose F (1996) Influence of storm disturbance on an offshore benthic community. Bull Mar Sci 59:523-529

> Pratt JR, Bowers NJ (1992) Variability of community metrics: detecting changes in structure and function. Environ Toxicol Chem 11:451-457

Quinn GP, Keough MJ (2002) Experimental design and data analysis for biologists. Cambridge University Press, Cambridge

Ragnarsson SÁ, Steingrímsson SA (2003) Spatial distribution of otter trawl effort in Icelandic waters: comparison of measures of effort and implications for benthic community effects of trawling activities. ICES J Mar Sci 60:1200-1215

Sanchez P, Demestre M, Ramon M, Kaiser MJ (2000) The impact of otter trawling on mud communities in the northwestern Mediterranean. ICES J Mar Sci 57:1352-1358

Sandin L, Johnson RK (2000) The statistical power of selected indicator metrics using macroinvertebrates for assessing acidification and eutrophication of running waters. Hydrobiologia 422/423:233-243

Schratzberger M, Dinmore TA, Jennings S (2002) Impacts of trawling on the diversity, biomass and structure of meiofauna assemblages. Mar Biol 140:83-93

> Schwinghamer P, Gordon DC Jr, Rowell TW, Prena J, McKeown DL, Sonnichsen G, Guigné JY (1998) Effects of experimental otter trawling on surficial sediment properties of a sandy-bottom ecosystem on the Grand Banks of Newfoundland. Conserv Biol 12:1215-1222

> Smith CJ, Papadopoulou N, Diliberto S (2000) Impact of otter trawling on an eastern Mediterranean commercial trawl 
fishing ground. ICES J Mar Sci 57:1340-1351

Thrush SF, Hewitt JE, Cummings VJ, Dayton PK and others (1998) Disturbance of the marine benthic habitat by commercial fishing: impacts at the scale of the fishery. Ecol Appl 8:866-879

Tuck ID, Hall SJ, Robertson MR, Armstrong E, Basford DJ (1998) Effects of physical trawling disturbance in a previously unfished sheltered Scottish sea loch. Mar Ecol Prog Ser 162:227-242

Underwood AJ (1994) On beyond BACI: sampling designs that might reliably detect environmental disturbances. Ecol Appl 4:3-15

Underwood AJ (1997) Experiments in ecology: their logical design and interpretation using analysis of variance. Cambridge University Press, Cambridge

Editorial responsibility: Lisandro Benedetti-Cecchi, Pisa, Italy
Wassenberg TJ, Dews G, Cook SD (2002) The impact of fish trawls on megabenthos (sponges) on the north-west shelf of Australia. Fish Res 58:141-151

Watling L, Findlay RH, Mayer LM, Schick DF (2001) Impact of a scallop drag on the sediment chemistry, microbiota, and faunal assemblages of a shallow subtidal marine community. J Sea Res 46:309-324

Wheeler AJ, Bett BJ, Billett DSM, Masson DG, Mayor D (2005) The impact of demersal trawling on northeast Atlantic deepwater coral habitats: the case of the Darwin Mounds, United Kingdom. In: Barnes PW, Thomas JP (eds) Benthic habitats and the effects of fishing. Am Fish Soc Symp 41:807-817

Winer BJ, Brown DR, Michels KM (1991) Statistical principles in experimental design, 3rd edn. McGraw Hill, Boston

Submitted: September 18, 2008; Accepted: April 09, 2009

Proofs received from author(s): May 30, 2009 